\title{
Efficient Market Hypothesis and the RMB-Dollar Rates: A Nonlinear Modeling of the Exchange Rate
}

\author{
Hongxing Yao ${ }^{1} \&$ Abdul Rashid Abdul Rahaman ${ }^{1}$ \\ ${ }^{1}$ School of Finance and Economics, Jiangsu University, Zhenjiang, P. R. China \\ Correspondence: Abdul Rashid Abdul Rahaman, School of Finance and Economics, Jiangsu University, 301 \\ Xuefu Road, Zhenjiang, P. R. China. Tel: 86-186-0524-1567/233-208-508-157. E-mail: sochibga1 @ yahoo.com
}

Received: November 27, 2017

Accepted: December 18, 2017 Online Published: January 20, 2018

doi:10.5539/ijef.v10n2p150

URL: https://doi.org/10.5539/ijef.v10n2p150

\begin{abstract}
This paper uses a SETAR model to determine threshold(s) in the RMB/US\$ exchange rate from 1981 to 2016 using monthly data. Also, it compares the forecast performance of the univariate nonlinear model to a univariate linear model. We further analyze the forecast performance of the SETAR model to a multivariate linear model, e.g., a Reduced-form VAR. In addition, the research assesses the claim by Boero and Marrocu (2002) that the root mean square error masks the superiority of the nonlinear models.

We found five significant thresholds in the RMB/US\$ exchange rate, and this result reflects five major episodes of policy reforms or structural changes in the renminbi exchange rates from the period 1981 to 2016. We also found that the univariate nonlinear model out performs both the univariate and multivariate linear models in predicting the exchange rate movements. This finding is consistent with the results in Kyei and Gyamfi (2016), Boero and Marrocu (2002), Krager and Kugler (1993), Peel and Speight (1994) and Chappell et al. (1996). Furthermore, we did not find any evidence of the root mean square error masking the superiority of the nonlinear model.
\end{abstract}

Keywords: Self Exciting Threshold Auto-regression (SETAR), Reduced-form Vector Autoregression (VAR), exchange rates, root mean square error, Renminbi

\section{Introduction and Background}

The RMB exchange rate has grown over the years to become one of the most traded currencies in the world (PBOC, 2011). It is also now one of the currencies used in the basket for calculating the IMF special drawing rights (Gomi, 2016). The currency is also now listed in most of the exchanges in the world, including the London Stock Exchange (LSE). The RMB is also on its way to becoming a reserve currency for many central banks in the world. For these reasons, knowledge of major episodes (thresholds) in the rmb/us $\$$ exchange rates, and how to model changes in the exchanges rate for proper forecasting is importance for reserve banks, and for global trade.

The idea of evaluating the forecasting performance of alternative models go back to the work of Meese and Rogoff (1983), who claimed the forecast performance of the random walk models is superior to the forecast performance of the complex structural equation models. However, a number of researchers have proved the work of Meese and Rogoff to be a puzzle, including the work of Wang and Wu (2009). Most of these researchers have stressed the importance of economic fundamentals in exchange rate determination. Edward (1988), Williamson (1991), Hinkle and Montiel (1999), Jin (2004) and Edison and Paul (1991) are among the numerous researchers who have tied up exchange rate determination to its fundamentals.

Several other studies have been conducted in the context of univariate models (Boero \& Marrocu, 2002). These studies exploit recent developments in nonlinear time series. They capture the dynamics in a variable time series and incorporate it into the model. The effectiveness of these models, however, is based on the theory of efficient market hypothesis. It is only when the market is efficient that one can assume that the current exchange rate embodies in it recent information(s) on the evolution of currency market. On the basis of this assumption, many researchers have also modeled exchange rates using univariate nonlinear models. According to Boero and Marrocu (2002), the commonly applied nonlinear models in literature are the generalized autoregressive conditional heteroskedastic (GARCH) model and the threshold models such as SETAR, STAR etc. One 
advantage of the nonlinear models is that they offer superior forecast over and above their linear counterparts, especially over medium and longer horizons (Krager \& Kugler, 1993; Peel \& Speight, 1994; and Chappell et al., 1996). The self-exciting threshold autoregressive (SETAR) models have also proved to be successful in describing the dynamic or nonlinear behavior of many economic and financial variables and they are also readily interpretable in economic terms (Boero \& Marrocu, 2002).

On comparison of the forecast performance of the linear and nonlinear models, Boero and Marrocu (2002), has also shown that, when attention is restricted to root mean square forecast errors (RMSE), the performance of the models tends to favour the linear models. This is because, the use of the root mean square forecast error (RMSE) may mask the superiority of the nonlinear models (Clement \& Smith, 1998).

Despite most researchers advocating for nonlinear modelling of financial and economic time series data, many still believe there is no clear cut advantage of nonlinear models over the linear models. Clement and Smith (1997) investigated a multi-period forecast performance of a number of SETAR models and have concluded that the nonlinear models only have an edge in certain states of nature, but not in others.

\subsection{Trend in Empirical works}

Research works on evaluation of forecast performance of alternative economic and financial models have evolved from comparisons between random walk models and Structural or simultaneous equation models to comparisons between structural or simultaneous equation models and univariate nonlinear models, and more recently, comparisons are made between univariate autoregressive models and the nonlinear models. In each of these models, majority of research works pick out nonlinear models over the structural or simultaneous models, the random walk models, and the univariate autoregressive models. No attention so far has been given to the evaluation of the forecast performance of the nonlinear models and the forecast performance of multivariate autoregressive (Reduced -form VAR) models proposed by Sims (1980).

This paper therefore compares the forecast accuracy or performance of nonlinear models to a number of multivariate autoregressive (reduce-form VAR) models. We also review previous research findings by fitting univariate linear autoregressive equations and comparing their forecast performance to the nonlinear SETAR model. We evaluate the forecast performance of the alternative models through Akaike Information Criterion (AIC) and also through the traditional evaluation method, that is, the root mean square forecast error (RMSE).

\section{Data and Methodology}

\subsection{Data}

We use monthly RMB exchange rate, from January 1981 to November 2016, in the univariate models. For the multivariate models, we used quarterly data from the first quarter of 1998 to the fourth quarter of 2015 . However, the SETAR model that we compared to the multivariate models was modelled using the quarterly data even though it is a univariate model. This was to facilitate the comparison of the univariate SETAR model to the multivariate models. Different data frequencies were use in this paper because of the unavailability of monthly data in some of the variables used in this research. The data was taken from the Federal Reserve Bank of St. Louis economic database.

\subsection{Methodology}

The methodology of this paper is arranged in a manner that will test for nonlinearity in the RMB exchange rate series using two test of nonlinearity. That is, the BDS test and also Tsay's test of nonlinearity. We then procedure to building a forecasting model for the RMB exchange rate using threshold autoregression (TAR) model if the Tsay F-test rejects the null of no threshold in the time series.

\subsubsection{Test of Linearity}

We conduct two test of nonlinearity on the time series; BDS test and Tsay test.

- BDS test:

The BDS test was developed by Brock, Dechert and Scheinkman (1987). It is arguably the most popular test for nonlinearity. Studies have shown that the BDS test can handle a wide range of linear and nonlinear models. It can be used as a test for linear dependence in time series. It can also be used as a test for nonlinear dependence as well as chaos in a time series. Kyei and Gyamfi (2016) have used BDS test to detect nonlinearity in stock market returns of the stock indices of Ghana and Nigeria. The procedure for conducting the BDS test is given below:

Let $\mathrm{Y}_{\mathrm{t}}$ be a time series with $\mathrm{N}$ observations; 


$$
\mathrm{Y}_{\mathrm{t}}=\left(\mathrm{Y}_{1}, \mathrm{Y}_{2}, \mathrm{Y}_{3}, \ldots, \mathrm{Y}_{\mathrm{N}}\right)
$$

It is important to note that $\mathrm{Y}_{1}, \mathrm{Y}_{2}, \mathrm{Y}_{3}, \ldots, \mathrm{Y}_{\mathrm{N}}$, are only observations in the time series $\left(\mathrm{Y}_{\mathrm{t}}\right)$. They are not different time series.

The time series $(\mathrm{Yt})$ is divided into an $\mathrm{m}$-dimensional vectors by selecting or choosing a number of successive observations for each $\mathrm{m}$-dimensional vector. The $\mathrm{m}$-dimensions, consisting of $\mathrm{m}$ successive observations, are called scalers.

The series of scalers is turned into a series of vectors with overlapping entries as below:

$$
\begin{aligned}
& Y_{1}{ }^{\mathrm{m}}=\left(\mathrm{Y}_{1}, \mathrm{Y}_{2}, \ldots, \mathrm{Y}_{\mathrm{m}}\right) \\
& \mathrm{Y}_{2}{ }^{\mathrm{m}}=\left(\mathrm{Y}_{2}, \mathrm{Y}_{3}, \ldots, \mathrm{Y}_{\mathrm{m}+1}\right) \\
& \mathrm{Y}^{\mathrm{m}}{ }_{\mathrm{N}-\mathrm{m}}=\left(\mathrm{Y}_{\mathrm{N}-\mathrm{m}}, \mathrm{Y}_{\mathrm{N}-\mathrm{m}+1}, \ldots, \mathrm{Y}_{\mathrm{N}}\right)
\end{aligned}
$$

The correlation integral $C_{\mathcal{E}, m}$, that is, the measure of spatial correlation among the points, is calculated by adding the number of pairs of points $(\mathrm{t}, \mathrm{j})$, where:

$\mathrm{I} \leq \mathrm{t} \leq \mathrm{N}$ and $\mathrm{I} \leq \mathrm{j} \leq \mathrm{N}$ in the $\mathrm{m}$-dimensional space which is "close" in the sense that the points are within a radius or tolerance $\varepsilon$ of each other.

$$
C_{\varepsilon, m}=\frac{1}{N_{m}\left(N_{m}-1\right)} \Sigma_{t \neq J} I_{t, j ; \varepsilon}
$$

Where $\mathrm{I}_{\mathrm{t}, \mathrm{j} ; \varepsilon}=1$ If $\left\|\mathrm{Y}_{\mathrm{t}}^{\mathrm{m}}-\mathrm{Y}_{\mathrm{j}}^{\mathrm{m}}\right\| \leq \varepsilon$

$$
=0 \quad \text { Otherwise. }
$$

BDS (1987) proved that if the time series is IID:

$$
C_{\varepsilon, m} \approx\left[C_{\varepsilon, I}\right]^{m}
$$

$\left[\mathrm{C}_{\varepsilon, \mathrm{m}}-\left(\mathrm{C}_{\varepsilon, \mathrm{I}}\right)^{m}\right]$ has an asymptotic normal distribution with zero mean and a variance $\mathrm{V}_{\varepsilon, \mathrm{m}}$ defined as:

$$
V_{\varepsilon, m}=4\left[k^{m}+2 \sum_{j=1}^{m-1} K^{m-j} C_{\varepsilon}^{2 j}+(m-1)^{2} C_{\varepsilon}^{2 m}-m^{2} K\left(C_{\varepsilon}^{2 m-2}\right)\right]
$$

Where $\mathrm{K}=\mathrm{K}_{\varepsilon}=\frac{6}{\mathrm{~N}_{\mathrm{m}}\left(\mathrm{N}_{\mathrm{m}}-1\right)\left(\mathrm{N}_{\mathrm{m}}-2\right)} \sum_{\mathrm{t}<\mathrm{j}<\mathrm{N}} \mathrm{h}_{\mathrm{t}, \mathrm{j}, \mathrm{N} ; \varepsilon} ; \mathrm{h}_{\mathrm{t}, \mathrm{j}}=\frac{\mathrm{I}_{\mathrm{t}, \mathrm{j} ; \varepsilon} \mathrm{I}_{\mathrm{j}, \mathrm{N} ; \varepsilon}+\mathrm{I}_{\mathrm{t}, \mathrm{N} ; \mathrm{\varepsilon}} \mathrm{I}_{\mathrm{N}, \mathrm{j} ; \varepsilon}+\mathrm{I}_{\mathrm{j}, \mathrm{t} ; \mathrm{i}} \mathrm{I}_{\mathrm{t}, \mathrm{N} ; \varepsilon}}{3}$

The BDS test statistic is therefore stated as:

$$
B D S_{\varepsilon, m}=\frac{\sqrt{N\left[c_{\varepsilon, m}-\left(c_{\varepsilon, I}\right)^{m}\right]}}{\sqrt{V_{\varepsilon, m}}}
$$

A bootstrapped p-value was estimated, though the sample was reasonably large and could account for any unusual distribution that has the potential of affecting the asymptotic normal distribution assumption of the series. This was mainly done to improve the strength of the BDS test.

Table 1. The result of the BDS independence test

\begin{tabular}{lccccc}
\hline $\mathbf{M}$ & $\mathbf{2}$ & $\mathbf{3}$ & $\mathbf{4}$ & $\mathbf{5}$ & $\mathbf{6}$ \\
\hline Bootstrapped p-value & 0.0000 & 0.0000 & 0.0000 & 0.0000 & 0.0000 \\
\hline
\end{tabular}

- $\quad$ Tsay Test:

The BDS Test is able to find the existence of nonlinearity either in the time series itself or through the residuals of a fitted time series model. Nonlinearity of a time series can be in different forms. Knowledge of the type or form of nonlinearity is important for the building of a model for a nonlinear time series (Tsay, 1991). According to Tsay (1991), the proposed test is an easy alternative for the state dependent model (SDM) proposed by Haggan et al. (1984) for the choice of model class. Tsay test or approach is good in determining if there is a threshold type of nonlinearity in the series. We therefore use the Tsay approach to test the null hypothesis that the time series $\left(\mathrm{Y}_{\mathrm{t}}\right)$ follows the SETAR model with $\mathrm{j}>1$.

Overcoming the difficulties in finding the threshold values, Tsay (1989) proposes a conventional F-test based on a fitted regression model or an arranged autoregression model.

We therefore present the Tsay test as in Hung et al. (2007):

Under the Tsay's arranged regression approach, the linear AR(p) model is regarded as the null model against the alternative SETAR model. 


\section{$\mathrm{H}_{\mathrm{o}}$; the time series is an $\mathrm{AR}(\mathrm{p})$ linear model \\ $\mathrm{H}_{\mathrm{A}}$; the time series is a SETAR model}

We consider an observed time series $\left\{Y_{t}, t=1,2, \ldots, n\right\}$. Let $h=\max (1, p+1-d)$ and denote $\pi i$ as the index of the ith smallest value among $\left\{\mathrm{Y}_{\mathrm{t}}: \mathrm{t}=\mathrm{h}, \mathrm{h}+1, \ldots, \mathrm{n}-\mathrm{d}\right\}$. The observations $\left\{\mathrm{Y}_{\mathrm{t}}: \mathrm{t}=\mathrm{h}, \mathrm{h}+1, \ldots, \mathrm{n}-\mathrm{d}\right\}$ are sorted in ascending order.

Both the dependent vector $\mathrm{Y}$ and the corresponding lagged design matrix $\mathrm{X}$ are arranged according to the threshold parameter $\mathrm{Y}_{\mathrm{t}-\mathrm{d}}$. Under the null hypothesis of linearity, the arranged autoregression is written in the form;

$\mathrm{Y}=\varnothing \mathrm{X}+\square$, where $\varnothing=\left\{\varnothing_{0}, \varnothing_{1}, \ldots, \varnothing_{\mathrm{p}}\right\}$ is a vector of the AR parameters and $\square$ is a vector of noise, that is:

$$
\left[\begin{array}{l}
\mathrm{Y}_{\pi 1+\mathrm{d}} \\
\mathrm{Y}_{\pi 2+\mathrm{d}} \\
\ldots \ldots \\
\mathrm{Y}_{\pi \mathrm{n}-\mathrm{d}-\mathrm{h}+1+\mathrm{d}}
\end{array}\right]=\left\{\begin{array}{ccc}
1 & \mathrm{Y}_{\pi+\mathrm{d}-1} & , \ldots, \mathrm{Y}_{\pi 1+\mathrm{d}-\mathrm{p}} \\
1 & \mathrm{Y}_{\pi \mathrm{i}-\mathrm{d}-1} & , \ldots, \mathrm{Y}_{\pi 2+\mathrm{d}-\mathrm{p}} \\
& \ldots & \ldots \\
1 & \mathrm{Y}_{\pi \mathrm{n}-\mathrm{d}-\mathrm{h}+1+\mathrm{d}-1}, \ldots, \mathrm{Y}_{\pi \mathrm{n}-\mathrm{d}-\mathrm{h}+1+\mathrm{d}-\mathrm{p}}
\end{array}\right]\left\{\begin{array}{c}
\emptyset_{0} \\
\emptyset_{1} \\
\ldots \\
\emptyset_{\mathrm{p}}
\end{array}\right]+\left\{\begin{array}{l}
\square_{\pi 1+\mathrm{d}} \\
\square_{\pi 2+\mathrm{d}} \\
\ldots \\
\square_{\pi \mathrm{n}-\mathrm{d} \mathrm{h}+1+\mathrm{d}}
\end{array}\right]
$$

Stepwise autoregression of the first $\mathrm{j}$ rows of $\mathrm{Y}$ on the first $\mathrm{j}$ rows of $\mathrm{X}$ is performed successfully for $\mathrm{j}=\mathrm{m}$, $\mathrm{m}+1, \ldots, \mathrm{n}-\mathrm{d}-\mathrm{h}$ where $\mathrm{m}>\mathrm{p}+1$ is the startup value.

Let $\chi_{j+1}$ be the $(j+1)$ th row of the $X$ matrix and $X j$ be the submatrix containing the first $j$ row of $X$. The corresponding one step ahead prediction residuals $\dot{\varepsilon}_{\pi \mathrm{j}+1+\mathrm{d}}$ are obtained successively,

$$
\dot{\varepsilon}_{\pi j+1+d}=\frac{Y_{\pi j+1+d^{-}} \hat{Y}_{\pi j+1+d}}{\sqrt{\left[1+\chi_{j+1}^{T}\left(X_{j}^{T} X_{j}\right)^{-1} \chi_{j+1}\right]}}
$$

Tsay's F-test is developed based on the orthogonality property between the predictive residuals given in equation(4) and the regressors:

$$
\left\{Y_{\pi j+1+d-v} V=1, \ldots, p, \quad j=1, \ldots, n-d-h-m\right\} \text { under the null hypothesis of linearity. }
$$

This property will be destroyed if observations that are lying in other regimes are involved, which in turn indicates non-linearity.

The orthogonality (thus the SETAR-type nonlinearity) can be tested by considering the regression model:

$$
\dot{\varepsilon}_{\pi j+1+d}=w_{0}+\sum_{v=1}^{p} w_{v} Y_{\pi j+1+d-v}+\mathrm{e}_{\pi j+1+d}
$$

For $\mathrm{j}=\mathrm{m}, \mathrm{m}+1, \ldots, \mathrm{n}-\mathrm{d}-\mathrm{h}$, i.e.,

$$
\left\{\begin{array}{l}
\dot{\varepsilon}_{\pi \mathrm{m}+1+\mathrm{d}} \\
\dot{\varepsilon}_{\pi \mathrm{m}+2+\mathrm{d}} \\
\cdots \\
\dot{\varepsilon}_{\pi \mathrm{n}-\mathrm{d}-\mathrm{h}+1+\mathrm{d}}
\end{array}\right]=\left[\begin{array}{cccc}
1 & \mathrm{Y}_{\pi \mathrm{m}+1+\mathrm{d}-1} & \cdots & \mathrm{Y}_{\pi \mathrm{m}+1+\mathrm{d}-\mathrm{p}} \\
1 & \mathrm{Y}_{\pi \mathrm{m}+2+\mathrm{d}-1} & \cdots & \mathrm{Y}_{\pi \mathrm{n}+2+\mathrm{d}-\mathrm{p}} \\
\cdots & \cdots & \cdots & \cdots \\
1 & \mathrm{Y}_{\pi \mathrm{n}-\mathrm{d}-\mathrm{h}+1+\mathrm{d}-1} & \cdots & \mathrm{Y}_{\pi \mathrm{n}-\mathrm{d}-\mathrm{h}+1+\mathrm{d}-\mathrm{p}}
\end{array}\right]-\left[\begin{array}{c}
\mathrm{w}_{0} \\
\mathrm{w}_{1} \\
\cdots \\
\mathrm{w}_{\mathrm{p}}
\end{array}\right]+\left[\begin{array}{c}
\mathrm{e}_{\pi \mathrm{m}+1+\mathrm{d}} \\
\mathrm{e}_{\pi \mathrm{m}+2+\mathrm{d}} \\
\cdots \\
\mathrm{e}_{\pi \mathrm{n}-\mathrm{d}-\mathrm{h}+1+\mathrm{d}}
\end{array}\right]
$$

The usual F-statistic of the regression in equation (...) is:

$$
F=\frac{M S S /(P+1)}{R S S /(n-d-h-m-p)}
$$

Where RSS $=\Sigma \mathrm{e}_{\mathrm{t}}^{2}$ and MSS $=\Sigma \dot{\varepsilon}_{\mathrm{t}}^{2}-$ RSS. Under the null hypothesis, the test statistic is asymptotically distributed as: $\mathrm{F}_{\mathrm{p}+1, \mathrm{n}-\mathrm{d}-\mathrm{h}-\mathrm{m}-\mathrm{p}}$

The results of the Tsay's F-test is presented in table 2 .

Table 2. The results of the Tsay's F-test

\begin{tabular}{llll}
\hline $\begin{array}{l}\text { Wald Test: } \\
\text { Equation: Untitled }\end{array}$ & & & \\
\hline Test Statistic & Value & df & Probability \\
\hline F-statistic & 548133.2 & $(7,411)$ & 0.0000 \\
Chi-square & 3836932. & 7 & 0.0000 \\
\hline
\end{tabular}

\subsubsection{Arranged Autoregressive AR(p) Model and Other Fitted Models}

The RMB exchange rate time series process is an AR(1) process; the ACF decays geometrically and the PACF is 
only significant for the first lag (see Table 3). A unit root test on the RMB exchange rate series shows the series to be stationary in level. Residual diagnostic tests were performed on a fitted AR(6) model, and the model was found not to have both serial autocorrelation and heteroscedasticity in the residuals, however, the residuals where not normally distributed. The non-normality of the residuals could be due to the sample size, and it is mostly improved by increasing the sample size of the data. Also, a stability diagnostic of the recursive estimates using CUSUM test was performed and the AR(6) model was found stable. A summary of the residual tests on AR(6) is found in Table 4.

The ARMA equation was also diagnosed and the fitted ARMA $(4,1)$ model was stationary and invertible. The ARMA frequency spectrum graph (see graph 1) also showed the residuals of the model to be a white noise. In addition to this, the estimates of the theoretical autocorrelation and partial autocorrelation in the ARMA structure are either zero or close to zero. These show the absence of serial autocorrelation in the model. A correlogram-Q-statistic could also be used to support the absence of serial autocorrelation in the model.

We also formulate a multivariate autoregressive linear model to test whether the complexity of a model (a nonlinear model) precedes the case of an increased parameter in linear modelling, in the form of an additional variable, in problem solving. The vector autoregressive model below is fitted to test the hypotheses:

$$
Y_{t}=\mu+\beta_{i j} \sum X_{(t-1)}+\varepsilon_{t}
$$

Where

$\mathrm{Y}$ is a $(\mathrm{K} \times 1)$ vector of dependent variables

$\mathrm{X}_{(\mathrm{t}-1)}$ is a ( $\left.\mathrm{K} \times 1\right)$ vector of lagged regressors (that is, exchange rate and foreign exchange reserves)

$\beta_{\mathrm{i}}$ is a coefficient matrix of the lagged regressors.

$\mu$ is a vector of constants or intercepts

$\varepsilon_{\mathrm{t}}$ is a vector of random shocks at time $\mathrm{t}$.

We have added one more variable $(k+1)$ to the linear $\mathrm{AR}(\mathrm{p})$ model, that is, foreign exchange reserves. Out of the numerous factors affecting the RMB rate, we have chosen to use the foreign exchange reserve because of the ubiquity of China's overwhelming reserves, and also because it reflects transactions in both current and capital accounts. This is in line with the opinion of Jin (2004). Jin (2004) uses foreign exchange reserves as a fundamental determinant of the RMB exchange rate. According to him, using foreign exchange reserve is an upgrade of the work of Edison and Paul (1991) who rather used cumulative current account balance.

The series for the foreign exchange reserve was found to be non-stationary in level. It was however found to be stationary in first difference. Table 6 and 7 show the test statistic. Table 8 shows the residuals diagnostics test of the vector autoregression (VAR) model, and shows the model is desirable.

We also fit the below multivariate linear autoregression model with added variables or parameters $(\mathrm{k}+2)$, where $\mathrm{k}$ is the number of variables used in the nonlinear SETAR (........) model.

$$
Y_{t}=\mu+\beta_{1} Y_{(t-1)}+\beta_{2} F x_{-} \operatorname{Resev}_{(t-1)}+\beta_{3} F C G L_{(t-1)}+\beta_{4} C I+\varepsilon_{t}
$$

Equation (8) has the general form:

$$
Y_{t}=\mu+\beta_{i j} \sum_{i=1}^{p} \mathrm{X}_{(\mathrm{t}-1)}+\varepsilon_{t}
$$

Where,

FCGL is foreign currency gains and losses

$\mathrm{CI}$ is a cointegrating equation between foreign exchange reserve of China and the foreign currency gains and losses.

The inclusion of the cointegrating equation in the model is to correct the error term in the model due to the presence of the cointegration (Jin, 2004).

This model was passed fit for the absence of both serial autocorrelation and heteroscedasticity (see table 8).

The variable 'foreign currency gains and losses' were computed as gains and losses from trade between China and CFETS countries. We adopted the approach in Jin and Choi (2013) for a two country (bilateral) scenario, and generalized his model to include multinational states scenario. The format below was used for the analysis:

$$
\operatorname{FxCGL}=\left\lfloor\frac{C_{t}\left(1+r_{t}\right)}{\varepsilon_{(t+1)}}\right\rfloor+\left\lceil\frac{C_{t}}{\varepsilon_{t}}\right\rfloor
$$


Where $\mathrm{C}=$ China's foreign Exchange reserves

$\mathrm{r}=$ Weighted Average Interest rate of CFETS countries

$\varepsilon=$ Weighted Average exchange rate of CFETS countries.

Table 3.

\begin{tabular}{|c|c|c|c|c|c|c|}
\hline \multicolumn{7}{|c|}{$\begin{array}{l}\text { Date: 04/13/17 Time: } 21: 16 \\
\text { Sample: } 1981 \mathrm{M} 01 \text { 2016M11 } \\
\text { Included observations: } 431\end{array}$} \\
\hline Autocorrelation & Partial Correlation & & $\mathrm{AC}$ & PAC & Q-Stat & Prob \\
\hline | $* * * * * * *$ & $\mid * * * * * * *$ & 1 & 0.984 & 0.984 & 420.41 & 0.000 \\
\hline $\mid * * * * * * *$ & $.1 . \quad \mid$ & 2 & 0.969 & 0.026 & 829.26 & 0.000 \\
\hline | $* * * * * * *$ &. & 3 & 0.955 & -0.003 & 1226.8 & 0.000 \\
\hline $\mid * * * * * * *$ &. & 4 & 0.941 & 0.009 & 1613.5 & 0.000 \\
\hline $\mid * * * * * * *$ &. & 5 & 0.928 & 0.029 & 1990.5 & 0.000 \\
\hline . $* * * * * * *$ &. & 6 & 0.915 & 0.013 & 2358.3 & 0.000 \\
\hline $\mid * * * * * * *$ &. & 7 & 0.903 & -0.006 & 2716.8 & 0.000 \\
\hline$|* * * * * *|$ &. & 8 & 0.891 & 0.016 & 3066.9 & 0.000 \\
\hline.$|* * * * * *|$ &. & 9 & 0.877 & -0.046 & 3407.4 & 0.000 \\
\hline.$|* * * * * *|$ &. & 10 & 0.864 & -0.011 & 3738.5 & 0.000 \\
\hline.$|* * * * * *|$ &. & 11 & 0.850 & -0.027 & 4059.7 & 0.000 \\
\hline.$|* * * * * *|$ &. & 12 & 0.836 & -0.017 & 4371.0 & 0.000 \\
\hline.$|* * * * * *|$ &. & 13 & 0.822 & 0.004 & 4672.9 & 0.000 \\
\hline.$|* * * * * *|$ &. & 14 & 0.809 & 0.013 & 4966.0 & 0.000 \\
\hline.$|* * * * * *|$ &. & 15 & 0.796 & -0.001 & 5250.6 & 0.000 \\
\hline.$|* * * * * *|$ &. & 16 & 0.784 & -0.007 & 5526.8 & 0.000 \\
\hline.$|* * * * * *|$ &. & 17 & 0.770 & -0.038 & 5794.0 & 0.000 \\
\hline.$|* * * * *|$ &. & 18 & 0.758 & 0.041 & 6053.4 & 0.000 \\
\hline$|* * * * *|$ &. & 19 & 0.746 & 0.011 & 6305.3 & 0.000 \\
\hline.$|* * * * *|$ &. & 20 & 0.734 & -0.003 & 6549.9 & 0.000 \\
\hline.$|* * * * *|$ &. & 21 & 0.722 & -0.002 & 6787.3 & 0.000 \\
\hline.$|* * * * *|$ &. & 22 & 0.711 & 0.007 & 7017.9 & 0.000 \\
\hline.$|* * * * *|$ & .1. & 23 & 0.700 & -0.008 & 7241.8 & 0.000 \\
\hline $\mid$. $|* * * *|$ & .1. & 24 & 0.687 & -0.048 & 7458.1 & 0.000 \\
\hline
\end{tabular}

Table 4. Summary of the residual tests on AR(6)

\begin{tabular}{|c|c|c|c|}
\hline \multicolumn{2}{|c|}{$\begin{array}{l}\text { Null Hypothesis: EXRATE has a unit root } \\
\text { Exogenous: Constant } \\
\text { Lag Length: } 6 \text { (Fixed) }\end{array}$} & \multirow[b]{2}{*}{ t-Statistic } & \multirow[b]{2}{*}{ Prob.* } \\
\hline & & & \\
\hline \multicolumn{2}{|c|}{ Augmented Dickey-Fuller test statistic } & -4.681216 & 0.0001 \\
\hline \multirow[t]{3}{*}{ Test critical values: } & $1 \%$ level & -3.445554 & \\
\hline & $5 \%$ level & -2.868137 & \\
\hline & $10 \%$ level & -2.570349 & \\
\hline
\end{tabular}

Note. *MacKinnon (1996) one-sided p-values.

Table 5. AR(6) residual diagnostic table

\begin{tabular}{lll}
\hline RESIDUAL DIAGNOSTIC & Chi-square probability for observed R-squared & Jarque- Bera probability test value \\
\hline Serial correlation LM Test & 0.9991 & NA \\
Heteroscedasticity test & 0.0892 & NA \\
Normality test & NA & 0.0000 \\
\hline
\end{tabular}


Table 6. Foreign exchange reserve series not stationary

\begin{tabular}{|c|c|c|c|}
\hline \multicolumn{4}{|c|}{$\begin{array}{l}\text { Null Hypothesis: FX_RESV has a unit root } \\
\text { Exogenous: Constant } \\
\text { Lag Length: } 1 \text { (Automatic - based on SIC, maxlag=11) }\end{array}$} \\
\hline & & $\mathrm{t}$-Statistic & Prob.* \\
\hline \multicolumn{2}{|c|}{ Augmented Dickey-Fuller test statistic } & -0.629961 & 0.8564 \\
\hline \multirow[t]{3}{*}{ Test critical values: } & $1 \%$ level & -3.527045 & \\
\hline & $5 \%$ level & -2.903566 & \\
\hline & $10 \%$ level & -2.589227 & \\
\hline
\end{tabular}

Note. *MacKinnon (1996) one-sided p-values.

Table 7.

\begin{tabular}{|c|c|c|c|}
\hline \multicolumn{4}{|c|}{$\begin{array}{l}\text { Null Hypothesis: D(FX_RESV) has a unit root } \\
\text { Exogenous: Constant } \\
\text { Lag Length: } 0 \text { (Automatic - based on SIC, maxlag=11) }\end{array}$} \\
\hline & & $\mathrm{t}$-Statistic & Prob.* \\
\hline \multicolumn{2}{|c|}{ Augmented Dickey-Fuller test statistic } & -3.102535 & 0.0309 \\
\hline \multirow[t]{3}{*}{ Test critical values: } & $1 \%$ level & -3.527045 & \\
\hline & $5 \%$ level & -2.903566 & \\
\hline & $10 \%$ level & -2.589227 & \\
\hline
\end{tabular}

Note. *MacKinnon (1996) one-sided p-values.

Table 8. Residual diagnostics summary table

\begin{tabular}{lllrll}
\hline & \multicolumn{2}{l}{ VECTOR AUTOREGRESSION MODEL (VAR) } & \multicolumn{2}{l}{ VECTOR ERROR CORRECTION MODEL (VEC) } \\
\cline { 2 - 5 } RESIDUAL DIAGNOSTIC & $\begin{array}{l}\text { Chi-square probability } \\
\text { for observed R-squared }\end{array}$ & $\begin{array}{l}\text { Jarque- } \\
\text { (probability test value) }\end{array}$ & $\begin{array}{l}\text { Chi-square probability } \\
\text { for observed R-squared }\end{array}$ & $\begin{array}{l}\text { Jarque- } \\
\text { (probability test value) }\end{array}$ \\
\hline Serial correlation LM Test & 0.0509 & NA & 0.2190 & NA \\
Heteroscedasticity test & 0.0948 & NA & 0.0726 & NA \\
Normality test & NA & $155.8197(0.0000)$ & NA & $175.6873(0.00000)$ \\
\hline
\end{tabular}

\subsubsection{Setar Model}

After the BDS Test and the Tsay's F-test have confirmed nonlinearity in the exchange rate time series, threshold nonlinearity is also detected in the series (Table 9). We therefore proceed to model the RMB exchange rate using the SETAR $(2,2,2)$ model, and then compare the forecast estimates of the model to the arranged autoregressive AR(6) model and also the ARMA(5,2) using Akaike Information Criterion (AIC).

The SETAR model has the general form:

$$
Y_{t}=\mu+\sum_{i=1}^{p} \emptyset_{i} X_{t-1}^{(j)}+\varepsilon_{t}, \text { If } \Gamma_{\mathrm{j}-1}<\mathrm{Z}_{\mathrm{t}-\mathrm{d}} \leq \Gamma_{j}
$$

Where:

$$
\begin{aligned}
& \mathrm{Y}_{\mathrm{t}} \text { is a }(\mathrm{k} \mathrm{x} 1) \text { vector of the dependent variables } \\
& X_{t-1}^{(j)} \text { is a (k x 1) vector of the lagged regressors } \\
& \emptyset_{\mathrm{i}} \text { is a ( } \mathrm{k} \mathrm{x} \mathrm{p)} \mathrm{coefficient} \mathrm{matrix} \mathrm{of} \mathrm{the} \mathrm{lagged} \mathrm{regressors} \\
& \varepsilon_{\mathrm{t}} \text { is a (k x 1) vector of residuals } \\
& \mathrm{Z}_{\mathrm{t}-\mathrm{d}} \text { is the threshold variable, and } \Gamma_{\mathrm{i}} \text { is the threshold value. }
\end{aligned}
$$

For the RMB exchange rate, the equation below describes the fitted SETAR $(2,2,2)$ model:

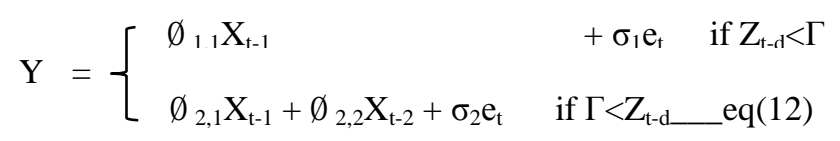


Table 9.

\begin{tabular}{lcccc}
\hline Thresholds & F-statistic & Scaled F-statistic & Weighted F-statistic & Critical Value \\
\hline $1 *$ & 4.783592 & 14.35078 & 14.35078 & 13.98 \\
2 & 3.437285 & 10.31186 & 12.02333 & 11.99 \\
3 & 2.561673 & 7.685020 & 10.34038 & 10.39 \\
4 & 1.917587 & 5.752761 & 8.886585 & 9.05 \\
5 & 1.526947 & 4.580842 & 8.584473 & 7.46 \\
\hline UDMax statistic* & & 14.35078 & UDMax critical value** & 14.23 \\
WDMax statistic & & 14.35078 & WDMax critical value** & 15.59 \\
\hline
\end{tabular}

Note. * Significant at the 0.05 level. ** Bai-Perron (Econometric Journal, 2003) critical values.

\section{Results and Discussions}

From the univariate model performance table 10, the Akaike information criterion (AIC) has selected the SETAR nonlinear model as the best model that describes the data generation process of the RMB exchange rate with the minimum loss of information. The result shows that, a univariate nonlinear model outperforms univariate autoregressive (AR) linear models in forecasting the RMB exchange rates. The results of the Root Mean Square Forecasting Error (RMSE) also give similar outcome. We therefore find it difficult to substantiate the claim of Boero and Marrocu (2002), and Clement and Smith (1997) that the RMSE masks the superiority of a model.

The superiority of univariate nonlinear models over univariate linear models, as in this research, is confirmed in most empirical works. For example, research by Kyei and Gyamfi (2016) confirms a univariate nonlinear modelling of stock market returns in Ghana and Nigeria to be superior to univariate linear models. This was probably why Gibson and Nur (2011) asserted that the nonlinear models are "natural progression" of the linear models. This finding in Table 10 only supports a case of equal variables in both types of models; that is linear and nonlinear. We therefore note that, given equal number of variables in a model, a nonlinear model outperforms the linear models.

\section{Non equal variables or parameters:}

Other researches have argued for variable or parameter addition when improving the fitness of a model. We see this reflecting in the value of the R-square whenever additional variables are added to a model. However, Akaike (1974) showed that a continuous increase can also lead to overfitting of the model. The AIC model therefore includes a penalty for overfitting. Akaike(1974) showed the AIC value to be a function of:

$$
A I C=2 K-2 \operatorname{In}(\breve{l})
$$

Where, $\breve{\iota}$ is the maximized value of the likelihood function of the model, i.e., $\breve{\imath}=\rho(x \mid \theta, M)$. Where $\theta$ are the parameter values that maximize the likelihood function, $\mathrm{x}$ is the observed data and $\mathrm{K}$ is the number of free parameters to be estimated.

On the account of variable or parameter additions improving the goodness of fit of a model, we tested the performance of the univariate SETAR model against two multivariate autoregressive (VAR) linear model and a three variable vector error correction (VEC) model. We added an additional variable (foreign exchange reserve) to the VAR model, and added two variables to the VEC model (that is, foreign exchange reserve and foreign exchange currency gains or loss from international trade). We added different number of variables (K) to the different multivariate models in other to make a case for two and three variables models.

The result of this finding still turns out to hold the univariate nonlinear SETAR model as the superior model. It is important to note that, this result does not mean the variable addition(s) to the autoregressive linear models did not improve the linear models. What the results simply tell us is that, the complexity or dynamics of time series data or variable should not be traded-off for additional variables or parameters in a model.

We are not making generalizations for all variables additions. Our analyses are on only two and three variables additions. If the need be, further research may be conducted on how many variables additions to a VAR linear model will make the model outperform a univariate nonlinear model.

Table 10. Univariate model performance sumarry

\begin{tabular}{llll}
\hline \multirow{2}{*}{ MODEL } & \multicolumn{2}{l}{ UNIVARIATE LINEAR MODELS } & \multicolumn{2}{l}{ UNIVARIATE NONLINAR MODEL } \\
\cline { 2 - 4 } & AR $(6)$ & $\operatorname{ARMA}(4,1)$ & SETAR $(2,2,2)$ \\
\hline AIC & -7.703343 & -7.705503 & -8.053513 \\
RMSE & 0.005057 & 0.005054 & 0.004254 \\
\hline
\end{tabular}


Table 11. Mix model performance summary

\begin{tabular}{llll}
\hline \multirow{2}{*}{ MODEL } & \multicolumn{2}{l}{ MULTIVARIATE LINEAR MODELS } & \multicolumn{2}{l}{ UNIVARIATE NONLINAR MODEL } \\
\cline { 2 - 4 } & $\operatorname{VAR}(2)$ & $\operatorname{VEC}(2)$ & SETAR $(5)$, \\
\hline AIC & -10.3433 & -10.38708 & -10.68053 \\
RMSE & 0.001277 & 0.001196 & 0.000852 \\
\hline
\end{tabular}

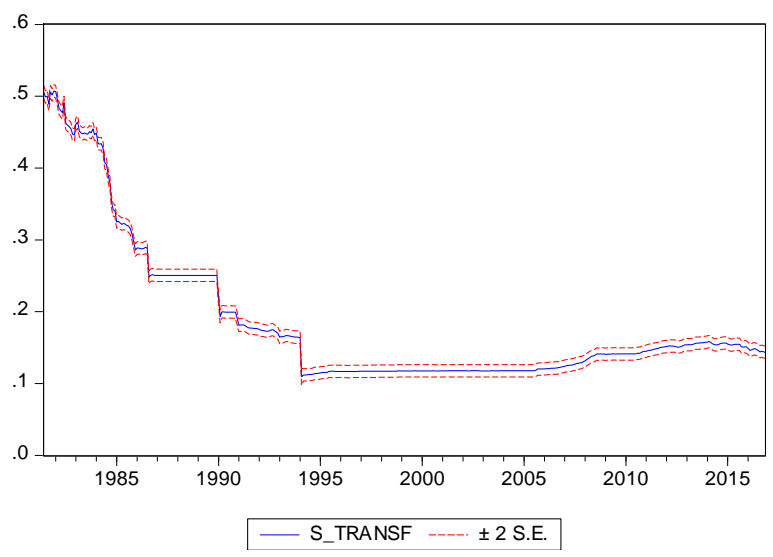

Forecast: S_TRANSF

Actual: S_TRANS

Forecast sample: 1981M01 2016M11

Adjusted sample: 1981M06 2016M11

Included observations: 426

Root Mean Squared Error $\quad 0.004254$

Mean Absolute Error $\quad 0.001596$

Mean Abs. Percent Error 0.730804

Theil Inequality Coefficient $\quad 0.009961$

Bias Proportion $\quad 0.000000$

Variance Proportion $\quad 0.000430$

Covariance Proportion $\quad 0.999570$

Figure 1a. SETAR $(2,2,2)$ Forecast Graph

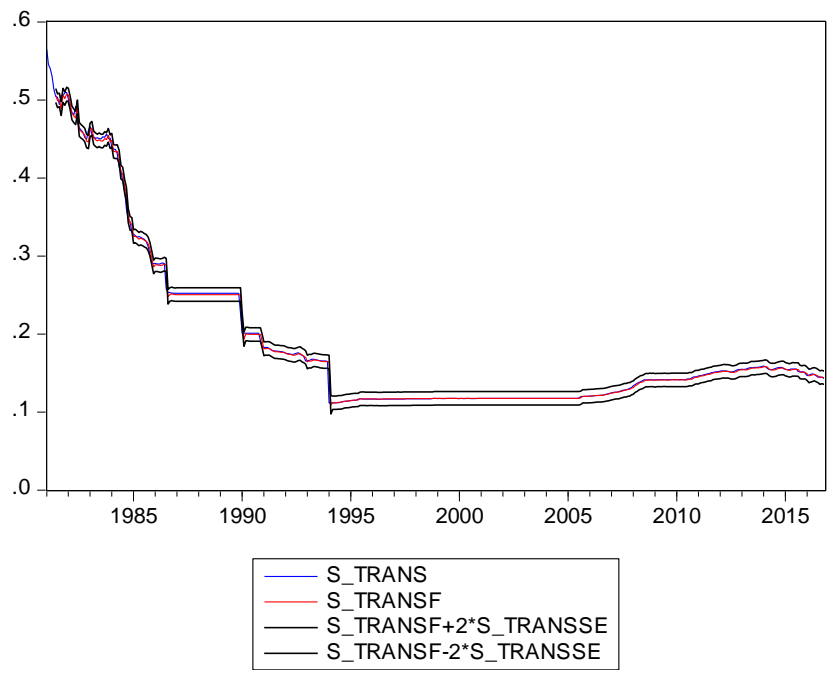

Figure 1b. SETAR $(2,2,2)$ Forecast and Actuals Comparison Graph

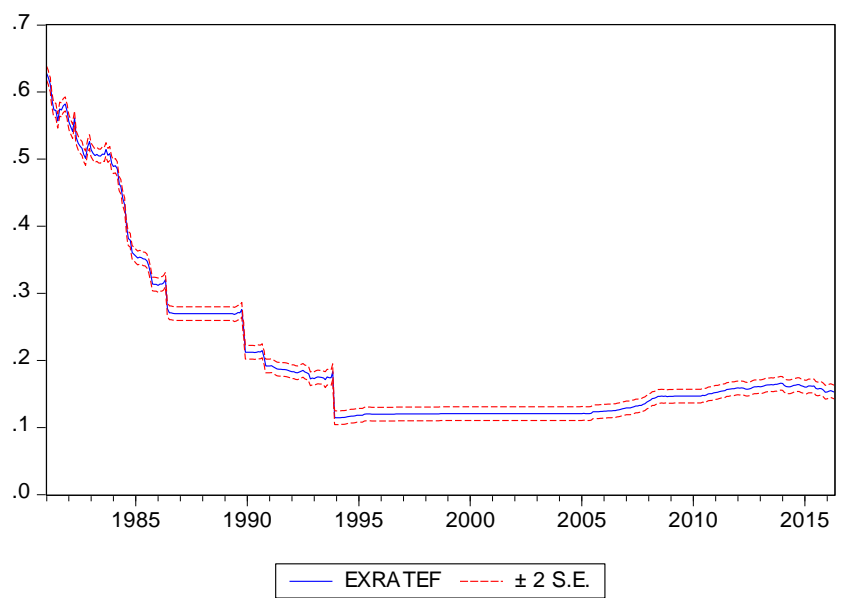

Forecast: EXRATEF

Actual: EXRATE

Forecast sample: 1981M01 2016M11

Adjusted sample: 1981M01 2016M05

Included observations: 425

Root Mean Squared Error $\quad 0.005057$

Mean Absolute Error $\quad 0.001839$

Mean Abs. Percent Error 0.670355

Theil Inequality Coefficient 0.010555

Bias Proportion $\quad 0.000000$

Variance Proportion $\quad 0.000408$

Covariance Proportion 0.999592

Figure 2a. AR(6) Forecast Graphs 


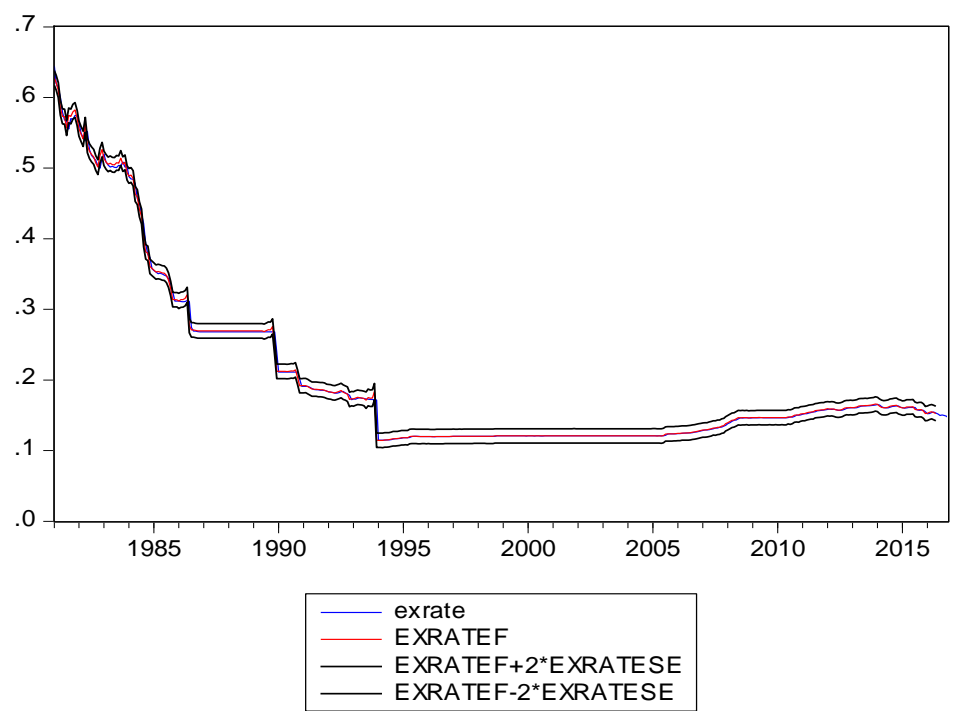

Figure 2b. AR(6) Forecast and Actuals Comparison

\section{Discussion}

The test result of the number of thresholds in the time series reveal five thresholds. This is a reflection of periods of major changes that the renminbi rates have gone through. From different currency regimes, to the merging of the official rates plus the market rate in 1994, to the depeging in 2005, and the events in the aftermath of the global financial crisis. The Asian financial crisis did not have a major effect on the renminbi rate (Jin, April 2003). These threshold periods summarizes the history of the renminbi rates which is important for policy.

Also, the result shows that, a univariate nonlinear model outperforms univariate autoregressive (AR) linear models in forecasting the RMB exchange rates. The results of the Root Mean Square Forecasting Error (RMSE) also give similar outcome. We therefore find it difficult to substantiate the claim of Boero and Marrocu (2002) and Clement and Smith (1997) that the RMSE masks the superiority of a nonlinear model. We therefore conclude that, given equal number of variables in a model, a nonlinear model outperforms the linear models.

Also, the results of the forecast performance of the nonlinear model and the multivariate autoregressive linear models still hold forecasting with a nonlinear model to be superior. This is seen in table 11 of the model summary performance table. What this result simply tells us is that, the complexity or dynamics of a time series data or variable should not be trade-off for additional variables or parameters in a model. The results also show that the renminbi market is efficient because, it is only when the market is efficient that one can assume that the current exchange rate embodies in it recent information(s) on the evolution of currency market.

\section{Acknowledgments}

The authors would like to thank the anonymous referees very much for their valuable comments and suggestions. This work was supported by the National Natural Science Foundation of China no. (71701082 and 71271103). This work would not have been possible without their support. We also thank all those who contributed in diverse ways in making the work complete.

\section{References}

Boero, G., \& Marrocu, E. (2002). The performance of non-linear exchange rate models: A forecasting comparison. Journal of Forecasting, 21(7), 513-542. https://doi.org/10.1002/for.837

Chappell, D., Padmore, J., Mistry, P., \& Ellis, C. (1996). A threshold model for the French franc/Deutschmark $\begin{array}{llllll}\text { exchange rates. Journal of } & \text { Forecasting, } & 15, & 155-164 .\end{array}$ https://doi.org/10.1002/(SICI)1099-131X(199604)15:3<155::AID-FOR616>3.0.CO;2-Z

Clements, M. P., \& Smith, J. (December 1997). A Monte Carlo study of the forecasting performance of empirical SETAR models. Warwick Economic Research Papers.

Clements, M. P., \& Smith, J. (March 1998). Nonlinearities in Exchange Rate. Warwick Economic Research Papers (No. 504).

Edison, H. J., \& B. Dianne, P. (1991). Re-Assessment of the Relationship Between Real Exchange Rates and 
Real Interest Rates: 1974-1990. International Finance Discussion Papers No. 408, Board of Governors of the Federal Reserve System.

Gomi, Y. (2016). A New Renminbi Index: The CFETS RMB Index. institute for international Monetary Affairs.

Gujarati, D. N. (2004). Basic Econometrics, Gujarati (4th ed.). McGraw Hills Companies.

Gyamfi, E. N., \& Kyei, K. A. (2016). Modeling Stock Market Returns under Self-exciting Threshold Autoregressive Model: Evidence from West Africa. International Journal of Economics and Financial Issues, 6(3), 1194-1199.

Hinkle, L. E., \& Peter, J. M. (1999). Exchange Rate Misalignment: Concepts and Measurement for Developing Countries. Oxford University Press.

Jin, H., \& Choi, E. K. (2013). Profits and losses from currency intervention. International Review of Economics \& Finance, 27, 14-20. https://doi.org/10.1016/j.iref.2012.08.013

Jin, Z. (April 2003). The dynamics of Real interest rates, Real exchange rates and the Balance of Payments in China. IMF Working Paper, WP/03/67.

Krager, H., \& Kugler, P. (1993). Non-linearities in foreign exchange markets: A different perspective. Journal of International Money and Finance, 12, 195-208. https://doi.org/10.1016/0261-5606(93)90024-6

Meese, R., \& Rogoff, K. (1983). Empirical exchange rate models of the seventies: Do they fit out of sample? Journal of International Economics, 14, 3-24. https://doi.org/10.1016/0022-1996(83)90017-X

Peel, D. A., \& Speight, A. E. (1994). Testing for nonlinear dependence in inter-war exchange rates. WeltwirtschaftlichesArchiv, 130, 391-417. https://doi.org/10.1007/BF02707716

People's Republic of China. (July 2011). From International Monetary Fund Washington, D.C.

Sims, C. (1980). Macroeconomics and Reality. Econometrica, 48, 1-48. https://doi.org/10.2307/1912017

Wang, J., \& Wu, J. J. (January 2009). The taylor rule and interval forecast for exchange rates. International Finance Discussion Papers (No. 963).

\section{Copyrights}

Copyright for this article is retained by the author(s), with first publication rights granted to the journal.

This is an open-access article distributed under the terms and conditions of the Creative Commons Attribution license (http://creativecommons.org/licenses/by/4.0/). 